mothers, a hostel attached to the Royal Free Hospital for girls and women requiring treatment for V.D. during pregnancy. All the patients were confined in the wards attached to the V.D. Department until the hostel closed in 1952.

Dr. Michael-Shaw was an active supporter of the Medical Society for the Study of Venereal Diseases. a council member, and during the session 1950-51 President of the Society, when she gave her presidential address on the subject of "Congenital Syphilis". She was also a member of the Venereologists' Group Committee of the B.M.A.

After the end of the war, in 1945, she visited V.D. clinics in Germany in her official capacity; the conditions she found were sometimes far from satisfactory and she was able to advise and help in her experienced and tactful way. As a result of her visit, several German venereologists came to Great Britain.

One of her great interests was the collecting of antique medical books, many of which were of particular interest to her as they dealt with her special subject. It is a matter of regret that this collection was dispersed when she retired.

Dr. Michael-Shaw was a devoted wife and mother and latterly very much enjoyed the company of her grandchildren. She died unexpectedly after an operation on October 28,1963 . The sympathy of her friends and colleagues goes out to her family.

J.S.

\title{
ROMAN ATLAS, 1910-1963
}

Dr. Roman Atlas died suddenly on December 24, 1963, at the age of 53 years. Born in Lwow (Poland), he graduated in 1934 and proceeded M.D. (Lwow) in 1938. He was interested in gynaecology, but in 1939, when war came, he joined the Polish Army in exile and with it came to England in 1940. He then transferred to the Royal Army Medical Corps and saw service in Great Britain, West Africa, India, and Belgium, becoming a graded specialist in venereal diseases. During the war our paths never crossed, but on several occasions I heard his name mentioned as a fellow venereologist in R.A.M.C. messes. In fact he replaced me at the British Military Hospital in Lucknow and after the war I succeeded him as clinical assistant at the Whitechapel Clinic of the London Hospital. It was not until 1950, however, that we finally met in the Department for Venereal Diseases at University College Hospital. In 1951 he was appointed assistant physician to the department for venereal diseases of the Prince of
Wales's Hospital, Tottenham, and there he remained until his untimely death.

He loved medicine, was a very able clinician, and took a particular interest in the social aspects of his specialty. He regularly attended meetings of the Medical Society for the Study of Venereal Diseases. He was always frank and said what he thought; brisk of movement and in temperament he was full of energy and down-to-earth humour, all of which made his sudden death the more unexpected. His outside interests were wide and revealed him as a man of culture; he loved the theatre, music, and literature, was a numismatist and a cactus-fancier. A proficient linguist, he travelled extensively on holidays and regularly attended medical meetings abroad.

He took a great pride in his lovely home and was a devoted husband and father. He had many friends within and outside the profession who will miss him and our deepest sympathy goes out to his widow and two young daughters.

G.J. 